\title{
Life-cycle based dynamic assessment of mineral wool insulation in a Danish residential building application
}

Sohn, Joshua L.; Kalbar, Pradip; Banta, Gary T.; Birkved, Morten

Published in:

Journal of Cleaner Production

Link to article, DOI:

10.1016/j.jclepro.2016.10.145

Publication date:

2017

Document Version

Peer reviewed version

Link back to DTU Orbit

Citation (APA):

Sohn, J. L., Kalbar, P., Banta, G. T., \& Birkved, M. (2017). Life-cycle based dynamic assessment of mineral wool insulation in a Danish residential building application. Journal of Cleaner Production, 142(4), 3243-3253.

https://doi.org/10.1016/j.jclepro.2016.10.145

\section{General rights}

Copyright and moral rights for the publications made accessible in the public portal are retained by the authors and/or other copyright owners and it is a condition of accessing publications that users recognise and abide by the legal requirements associated with these rights.

- Users may download and print one copy of any publication from the public portal for the purpose of private study or research.

- You may not further distribute the material or use it for any profit-making activity or commercial gain

- You may freely distribute the URL identifying the publication in the public portal 


\section{Life-cycle based Dynamic Assessment of Mineral Wool Insulation in a Danish Residential Building Application}

Joshua L. Sohn ${ }^{A}$, Pradip P. Kalbar ${ }^{B}$, Gary T. Banta ${ }^{A}$, and Morten Birkved ${ }^{B}$

A Roskilde University, Department of Environmental, Social and Spatial Change, Roskilde, Denmark

jlsohn@ruc.dk, banta@ruc.dk

B Technical University of Denmark, Department of Management Engineering, Lyngby, Denmark kalbar@dtu.dk, birk@dtu.dk

Corresponding author:

Pradip P. Kalbar

Quantitative Sustainability Assessment Division

Dept. of Management Engineering

Technical University of Denmark (DTU)

Produktionstorvet

Building 424, room 231

2800 Kgs. Lyngby

Denmark

Tel. No.+45 45254607

Email Address: kalbar@dtu.dk; pradipkalbar@gmail.com

\section{Abstract:}

There has been significant change in the way buildings are constructed and the way building energy performance is evaluated. Focus on solely the use phase of a building is beginning to be replaced by a life-cycle based performance assessment. This study assesses the environmental impact trade-offs between the heat produced to meet a building's space heating load and insulation produced to reduce its space heating load throughout the whole life-cycle of a building. To obtain a more realistic valuation of this tradeoff, a dynamic heat production model, which accounts for political projections regarding change in Danish energy supply was used in the analysis. This novel approach of generating inventory for Life Cycle Assessment (LCA) helped to refine an understanding 
of optimal insulation levels. The findings of this study discourage the over-insulation of houses connected to the district heating grid, which is being potentially promoted at present in Danish regulation. It is further concluded that improvement of the mineral wool insulation production process could allow for greater levels of environmentally beneficial insulation and would also help in reducing the overall environmental burden from insulating buildings.

\section{Keywords:}

Building Sustainability; Building Insulation; Energy Systems; Life Cycle Assessment; Dynamic Assessment; Climate Change

\subsection{Introduction}

The understanding of environmental performance of buildings has changed significantly in recent years. Focus of analysis has entirely shifted from the use phase of a building to a more holistic approach including construction, use, and in some cases end-of-life phase (Sartori and Hestnes 2007). Historically, the embodied environmental impacts, and in particular climate change potential, of building components have been generally disregarded due to their relative insignificance compared to the impacts related with energy consumption during use (Ibn-Mohammed et al. 2013). In recent years, however, building components have become more important in the overall building energy and environmental performance analysis due to the increased prevalence of high performance 'low-energy' buildings (Sartori and Hestnes 2007), and the optimization of building envelopes using LCA has been identified as a priority (Azari et al., 2016). At the same time as buildings have increased their operating efficiency, there has been significant effort to 
reduce the environmental impact of energy production. Despite this, there is still substantial dependency on fossil fuels in the global energy supply, and such reliance is expected to persist for the coming decades (Armor 2007). But, in some specific markets, such as Denmark, the change in energy supply mix over the last several decades has been significant and is expected to continue to change over the coming decades reducing the overall environmental impact of energy production (Danish Energy Agency 2015; Danish Energy Agency 2011).

\subsection{The use of insulation}

For years, the insulation market in Europe has been dominated by mineral wool $(57 \%)$ and polymer-based materials (40\%) like expanded polystyrene, extruded polystyrene, and polyurethane. Recently, a few other materials have also appeared such as cellulosic insulation materials like flax or paper wool (3\%). But, particularly in Northern Europe mineral wool tends to dominate the market (Schmidt et al. 2004). Because of its importance, mineral wool insulation has been assessed in a number of recent publications, such as in Papadopoulos \& Giama (2007) and Schmidt et al. (2004). Furthermore, Schmidt et al. (2004) concluded, in their life cycle assessment of various building insulation materials, that mineral wool insulation and paper wool insulation exhibited the lowest potential for environmental impacts of the insulation types they tested. Schiavoni et al. (2016) also indicate that mineral wool exhibits lower global warming potential than many other types of insulation. Because of this advantageous environmental reputation, its relatively low environmental impacts as well as large market share, this study focuses on mineral wool as a first test case in assessing the use of insulation for residential buildings in Denmark. 


\subsection{Balancing insulation quantity versus energy use over the life cycle of building}

When assessing the optimal level of insulation for a given application, it has often been assumed that the amount of energy required for insulation material production weighed against energy requirements for space heating over the lifetime of a building would give a good idea of an environmental optimum. Such comparisons have been widely made both in terms of economic impact and energy balance (Kaynakli 2012) showing diminishing returns as the level of insulation increases. The change in energy supply towards a less environmentally burdensome energy supply mix in some markets has resulted in these types of simple calculations no longer being valid proxies for such total impact comparisons (Gustavsson and Joelsson 2010). On the other hand, a life cycle assessment approach balancing the environmental impact of heat production for the lifetime of the building and the environmental impact of the building's insulation gives better insight into the optimization of building insulation levels. This relationship can be well represented by a total life cycle impact curve (Figure 1). 


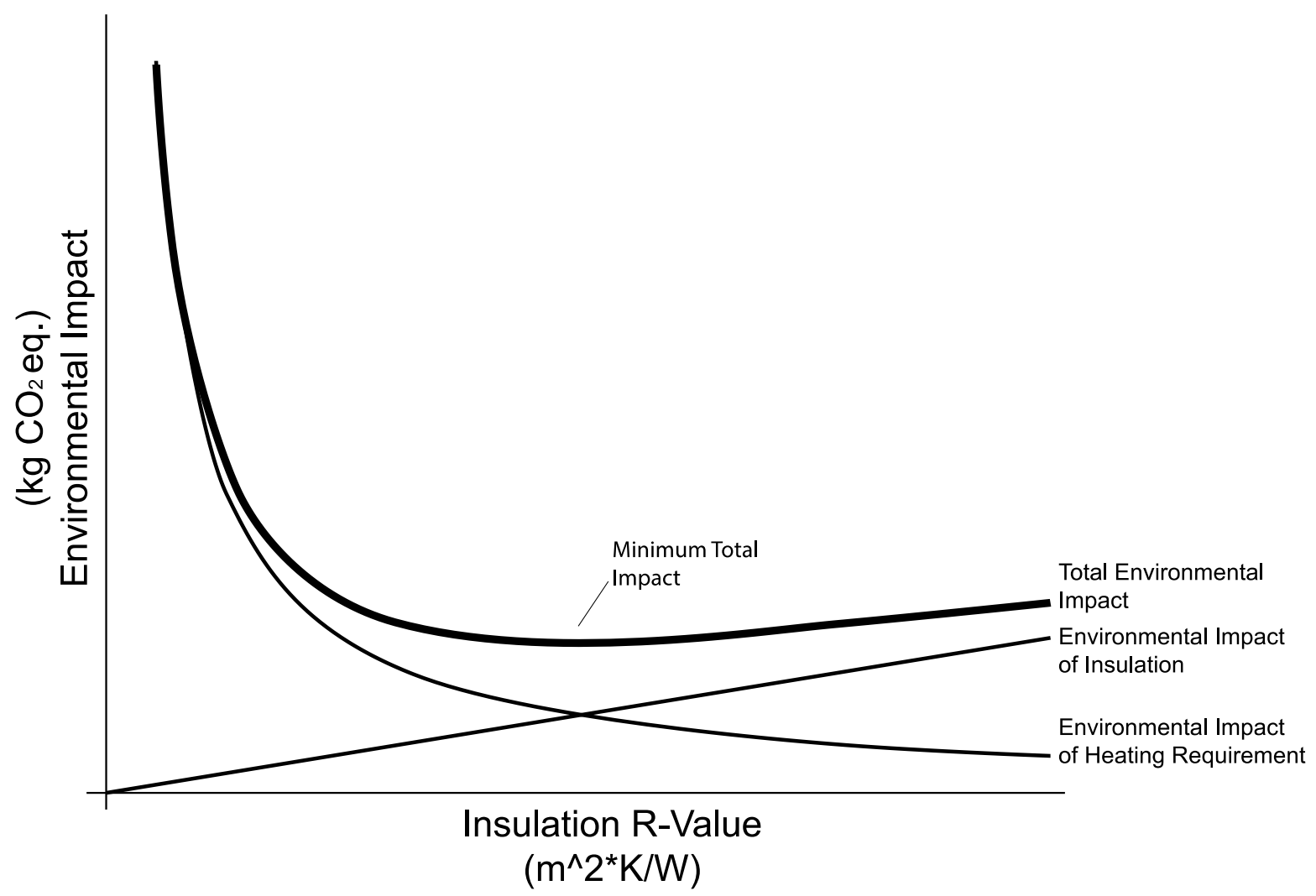

Figure 1: Total life cycle impact curve relating building insulation and lifetime heat requirement (adapted from Richman Pasqualini and Kirsh 2009)

\subsection{The dynamic nature of energy mix}

The constant change in building heat supply complicates an accurate quantification of an optimal insulation level. To facilitate such assessments, buildings are often assumed to have an average service life of 50 years, or in some cases even longer (Sartori and Hestnes 2007). Because of buildings' longevity, new buildings are expected to consume a changing, dynamic energy mix, such as the mix forecasted to be delivered in the coming decades in Denmark (Danish Energy Agency 2011). If the environmental impacts of providing heat for a building during it's use are assessed based on the current energy mix, then the estimation of the lifetime environmental impacts of heating a building will most likely be incorrect. Without taking temporal shifts of the energy mix into account, building 
regulations and other incentives might promote levels of insulation that are limited in scope/unrealistic and hence not necessarily environmentally beneficial. This can occur because the projected benefits of the energy mix due to the temporal shifts are not quantified in static assessment, which fails to address the reduced impact of heating with an increasingly renewable and other cleaner energy technologies energy mix share throughout the service life of a building (Figure 2).

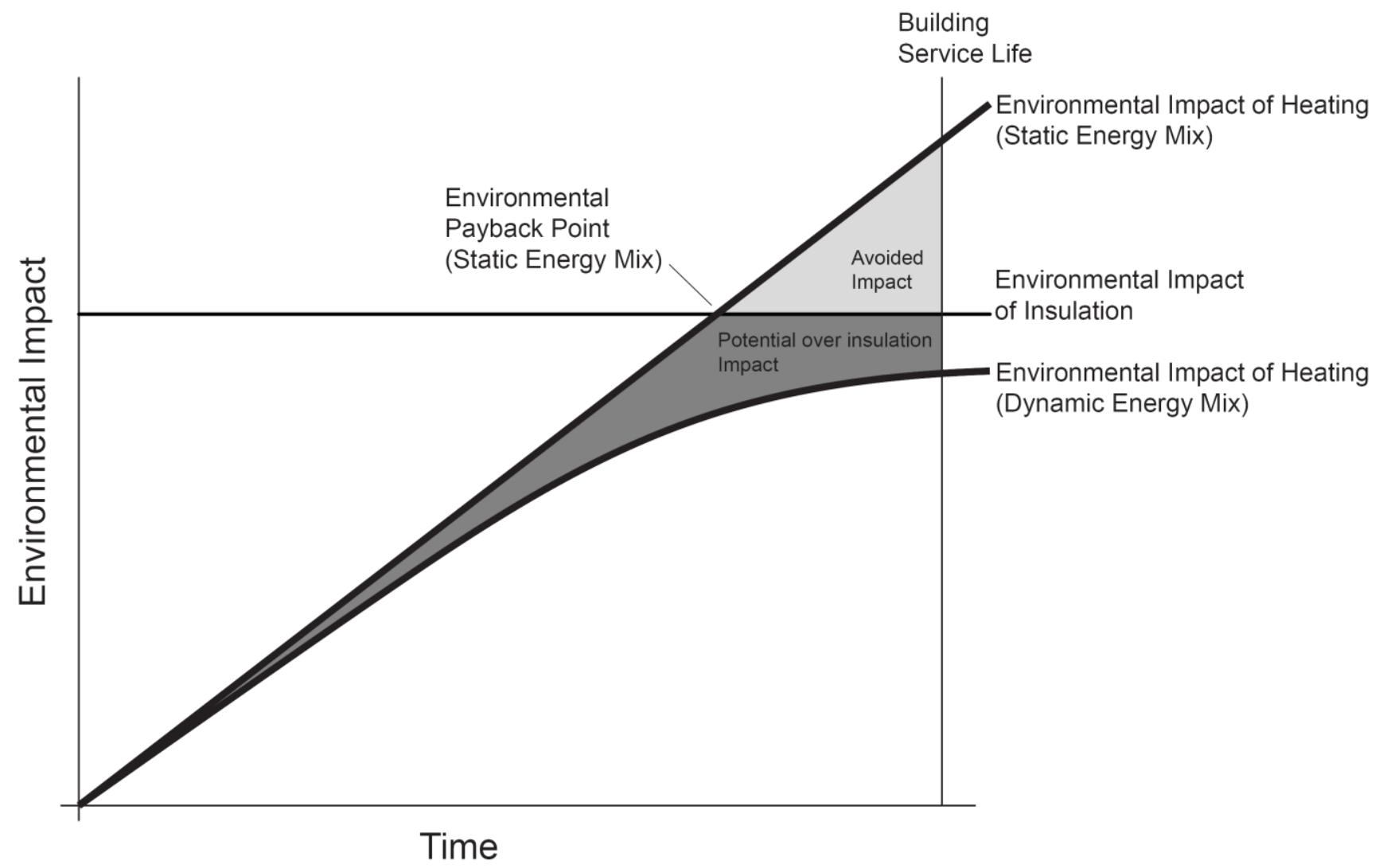

Figure 2: Potential environmental impact of over insulation based on optimization for static energy mix versus optimization for dynamic energy mix projection

\subsection{The need for a dynamic assessment}

In Denmark, building regulations and energy policies promote a reduction in the energy needs of buildings while also setting out a plan for progressing toward a cleaner energy 
mix (DEV 2010; DEA 2015; DEA 2011). The Danish building regulations, in addition, only refer to the use phase of a structure without provision for the embodied environmental impact of insulation materials (Aggerholm 2013). This, coupled with Denmark's history of a progressive energy mix and commitment to an even further reduced environmental impact from its energy supply in the coming decades, makes Danish residential buildings an ideal test case for issues that could potentially be relevant in other markets that either have, are beginning, or are planning for similar energy use reductions and cleaner energy production goals in their regulatory frameworks.

Because of the differences between the energy mix used for production of insulation and the production of heat to meet building's space heating load, as well as the changes in energy mix used for heating over time, the optimum levels of insulation are not well understood and can be hard to quantify if only relying on a use phase energy balance. Given the overall impact of the residential sector in relation to national energy usage, understanding this relationship is vital to the promotion of a more sustainable society (Gustavsson and Joelsson 2010; Cuéllar-Franca and Azapagic 2012). In order to achieve that understanding, this study focuses on assessing the balance between the potential impact contributions to climate change resulting from the use of varying levels of mineral wool insulation and providing respective amounts of space heating required by a representative Danish single family home.

\subsection{Methodology}

This study balances the environmental impacts induced (i.e. by production of insulation material) and saved (i.e. via reduced energy demand) by insulating a representative Danish single family home in the form of a Danish reference house (Aggerholm 2013) with the environmental impacts induced by energy consumption from heating the home over 
the course of the entire service life of the house. To accomplish this assessment, a multistage methodology was employed, which includes 1) estimating insulation quantity used in the construction of the Danish reference single family home to meet various regulatory energy use levels as outlined in BE10, the Danish building code (DEV 2010), 2) estimating energy consumption for space heating given each respective insulation Level, and 3) an LCA quantifying the environmental impact potentials of the insulation and energy consumption including a dynamic energy grid model. All the details related to standard reference house considered for present study, description of articulated insulation scenario details of district heat mix, details of building energy model and description of insulation and energy scenarios are provided in Section 1 of the Supplementary Information (SI).

\subsection{Life cycle assessment of DREM scenarios}

LCA of the Danish Reference house and Danish Energy mix (DREM, as described in Tables S1 and S2 in the SI) insulation scenarios was carried out to assess the environmental impact balance between insulation quantity and energy consumption for building area heating. Considering this objective, the functional unit for the LCA was chosen as a 'single family detached home heated to $20^{\circ} \mathrm{C}$ with a 50 -year service life'. In the past, life cycle assessment of insulation materials has most often been calculated based on a functional unit of a specific thermal resistance for a specified area (e.g. 1 $\mathrm{m}^{2} \mathrm{~K} / \mathrm{W}$ ) (Schmidt et al. 2004). While it is an appropriate measure for comparison of insulation products, this functional unit does not capture the relationship between varying levels of insulation and building heat requirements. In order to understand this relationship, a whole building was used. In some research, existing whole buildings have been analyzed (Gustavsson and Joelsson 2010). This method is ideal for producing highly 
accurate results, but it does not provide the possibility to test varying insulation scenarios. For the purposes of our study, the whole building dynamic assessment is carried out using a model building representing average Danish residential construction with energy losses calculated with BE10v7 (Aggerholm and Sørensen 2016), which allowed for complete control of all parameters as well as comparability across insulation scenarios.

The system boundaries of our study are represented in Figure 3. It covers production of insulation material required to insulate the Danish single family reference home and the Danish district heating system used to provide space heating for the house. Also, additional roof material and facade cladding material consumed as a consequence of the varying insulation thicknesses for each of the DREM scenarios were considered. It is assumed that the majority of the waste material would be landfilled and the remainder would be recycled, but due to lack of specific data the end-of-life phase of the insulation material was not considered as part of the evaluation (Väntsi and Kärki 2014).

The OpenLCAv1.4.1 product-system modelling software (Green Delta 2015) with the Ecoinvent 3.2 attributional (at the point of substitution) database (Weidema et al. 2013) was used for assessing impacts. The modelling approach assesses the relative marginalimpact of the DREM scenarios, thus it disregards any common elements present across all scenarios (Figure 3). It is also assumed that the marginal building materials necessary for construction of each respective insulation scenario, such as additional bricks or roof tiles would have an insignificant effect on the total impact on the installation processes during the actual construction of the building. So, any potential increased environmental impacts induced by the installation process for the marginal construction materials are disregarded. 


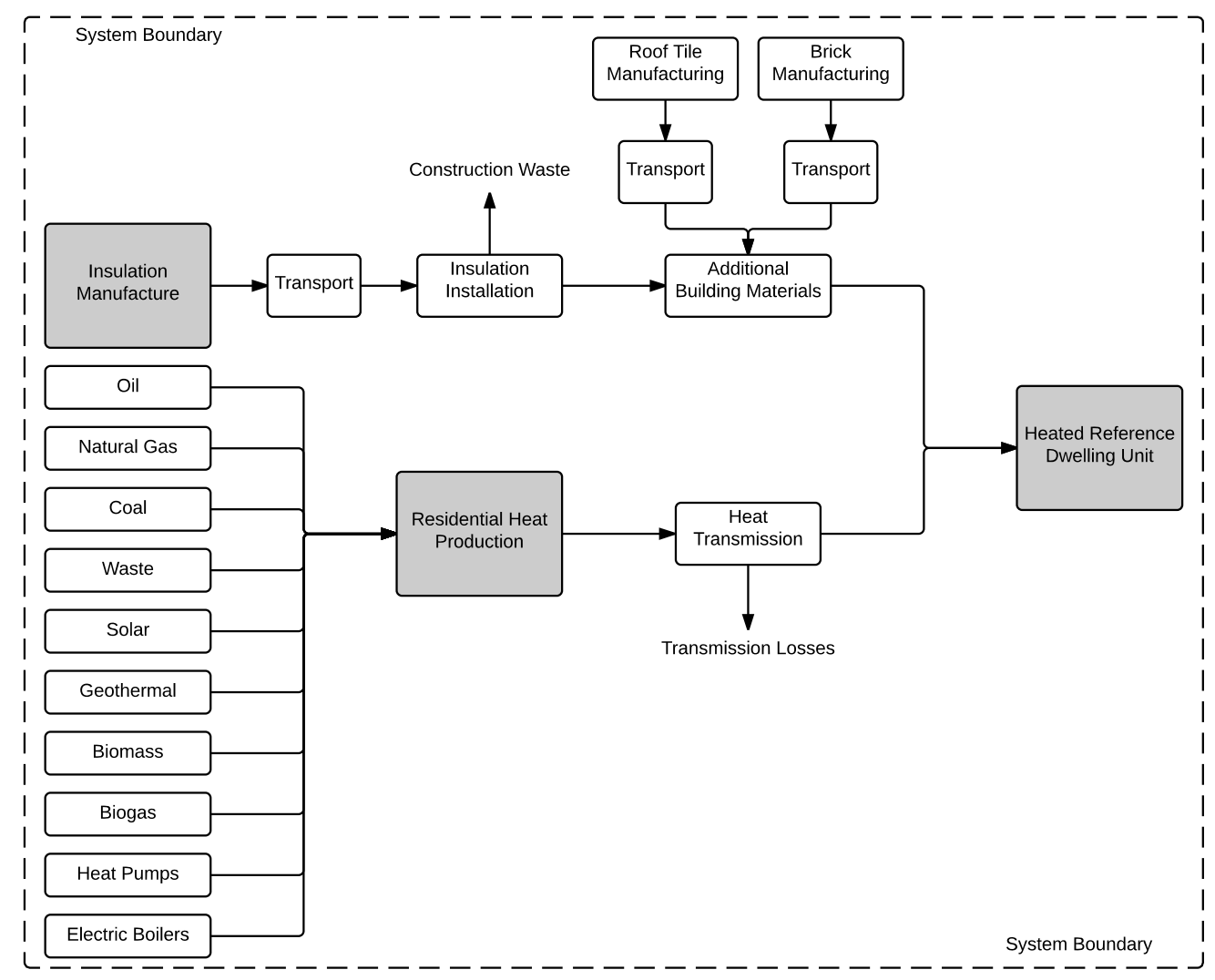

Figure 3: System boundary of LCA of balance of insulation verses heating requirement of the building over the life time.

\subsection{Modelling energy consumption}

There are ten main energy sources that are considered significant, and used in the definition of, the current Danish heat supply mix in Danish heat supply reports (Energistyrelsen 2015) and projections hereof (Energistyrelsen 2015; Rasmussen, 2012). The 24 energy sources present in the historical production source data reported by Energistyrelsen (2015) were grouped to match the 10 main sources in the heat mix projections and the groupings in the yearly energy consumption reports (Energistyrelsen 2015). Appropriate processes available in the Ecoinvent 3.2 database were used to model these main sources (see Table S5). When representative Danish processes were not available, Swiss $(\mathrm{CH})$ or Europe without Switzerland (RER) processes were chosen. Also, 
due to the prevalence of combined heat and power (CHP) production, which accounted for nearly $70 \%$ of the annual production in 2014 , as well a trend toward increased production of district heat in CHP plants in Denmark over the last 25 years and a political commitment to increase this amount in the future, CHP energy production processes were chosen for fuel-based heat production instead of conventional heat production facilities (Energistyrelsen 2015; DEA 2011). The result of this approach is that the impacts of heat production are allocated amongst the heat production and electricity production, which results in a lower impact from heat production than would be found in conventional heat production. It was also assumed that there is an average transmission loss of $20 \%$ in the Danish district heating system (DEA 2014).

For the waste, biogas, and electric boilers processes, user-defined (i.e. custom) processes were created. Waste and biogas were created to provide energy with no impacts allocated to the heat production process. This was done because their impacts are attributed to the life cycle of the products that the waste material came from, so accounting for them in the heat production would amount to a double accounting of their environmental impact (Gentil and Aoustin 2009). And finally, the electric boiler process was created using a $98 \%$ efficient conversion of electricity to heat, which accounts for a 100\% efficient energy conversion with some losses due to faulty wiring and poorly designed ducting passing through unconditioned spaces in some instances (EIA 2012).

\subsection{Modeling insulation material}

The addition of insulation leads to a slightly larger building structure, which in turn requires some additional building materials. While it would be difficult, if not impossible, to account for all of the marginal minor building materials (e.g. mortar, nails, and caulking) that would be necessary for construction in each of the DREM scenarios, some of the major elements 
(i.e. bricks and roof tiles) can be accounted for likely representing the majority of the environmental impact of each insulation scenario's respective marginal building materials. The environmental impacts potentials of these additional building components were calculated using the Ecoinvent 3.2 processes presented in Table S6 in the SI. The environmental impacts potentials of transportation were quantified based on the mass of the insulation, bricks, and roofing tiles using the appropriate Ecoinvent 3.2 transport processes. It was assumed that transported items would travel $200 \mathrm{~km}$ from their production site to the construction site. This distance was based on the approximate average distance from a mineral wool production plant in southern Jutland to the four largest cities in Denmark (Copenhagen, Aarhus, Odense, and Aalborg). The same distance was used for the transportation of (additional) marginal building materials. While it is likely that actual transportation distances in some cases may vary from our estimated distances, the transportation process accounts for a very small fraction of the overall impacts of the building system, and such variance is hence not expected to have a significant impact on final results.

The environmental impact of mineral wool was calculated using the standard Ecoinvent 3.2 mineral wool production process available in 'rock wool, packed | rock wool production, packed - $\mathrm{CH}^{\prime}$. The amount used in each insulation scenario was determined by a mass calculated using a representative value for low bulk density range mineral wool insulation of $41 \mathrm{~kg} / \mathrm{m}^{3}$ (pls. see Table S1 in the SI), as defined in the German Rockwool EPD (Deutsche Rockwool 2012). It was also assumed that the insulation scenarios would require 5\% more mineral wool than the amount geometrically required for construction due to trimming waste during building construction (Väntsi and Kärki 2014). Although this mineral wool production process is described in the Ecoinvent database process 
description as representative for mineral wool with a range of densities, as there are only negligible differences such as in the post wool fiberization process which result in negligible energy consumption differences in the production process within the range of low to medium low density mineral wool, the applied Ecoinvent process assumes a medium-low product density of $100 \mathrm{~kg} / \mathrm{m}^{3}$ (Weidema 2013). The resulting inconsistency introduced by applying the Ecoinvent 3.2 process for Rockwool as representative for $41 \mathrm{~kg} / \mathrm{m}^{3}$ density mineral wool applied in our study is that the impact contribution from the mineral wool packaging material demand is slightly underestimated, as the $41 \mathrm{~kg} / \mathrm{m}^{3}$ density mineral wool has greater volume per ton than $100 \mathrm{~kg} / \mathrm{m}^{3}$ density mineral wool, and thus would require more pallets and plastic wrap covering.

All DREM insulation scenarios, described in the SI Table S1 and Table S2, were assessed in OpenLCA with dynamic energy mixes based on construction year (1972 dynamic and 2015 dynamic). For the 2015 construction year scenario, a static energy scenario was also performed (2015 static), where the proportions of the 10 different energy sources accounted for were fixed at the 2015 values. A scenario simulating construction in 1972 with all DREM scenarios was also tested to allow for the use of only measured data. For this 1972 construction year scenario, the energy mix was quantified using the actual reported energy mix from 1972-2014. An average of each of the years in this range was used to represent the dynamic energy mix, used for the 1972 dynamic energy scenario (1972 dynamic). A static energy scenario with energy source proportions fixed at the 1972 values was also carried out (1972 static) for comparison with 1972 dynamic. The use of the average of 42 years of reported data, due to the lack of data before 1972 and instead of using projected data for the years 2015-2022, results in the 42 years of energy mix change being effectively stretched to fit over the 50-year service life of the 
reference house. Because there would likely have been greater change in the energy mix if 50 years of data were available, this might result in a less dramatic difference between the static and dynamic energy mix scenarios than could potentially be expected. Because of this likely-reduced difference, a comparison of the dynamic and static 1972 scenarios should result in a conservative estimation of the importance of the use of a dynamic energy mix, as it will appear as though less change in the energy mix occurred than actually did or probably will.

Finally, the impact assessment method ILCD 2011 was used to estimate the impacts at midpoint level. This method was chosen because of its common usage and the recommendation for use of the ILCD method as the 'state of the art' for assessing products and services (Hauschild et al 2013; European Commission 2010).

\subsection{Results}

The LCIA results for the four groups of scenarios were estimated for all impact categories, please refer to Table S7 in Section 2 of SI. However, due to significant variations among the scenarios including opposing impact trends in the scenarios, the midpoint for climate change was chosen as a key indicator for comparison based on its relevance to political goals laid out in the Danish energy plans (DEA 2011). This simplifying choice thus allows for the use of only one impact category indicator for insulation optimization based on midpoint climate change impact. The midpoint results for all 4 scenarios results, summarized in Table S7 (in the SI), include a comparison of the climate change burden resulting from a static energy mix and a dynamic energy mix for both the 1972 and 2015 construction year scenarios.

A life cycle impact curve, as hypothesized in Figure 1, was developed for the 2015 construction year scenarios comparing the ILCD 2011 midpoint for climate change impacts 
with static and dynamic energy supply scenarios (please see Figure 4). The differences between the curve representing the static and dynamic energy supply scenarios are indicative of the potential for inadvertent conservative assessment of the impacts of providing heat. This conservative assessment approach, along with the illustration of the differences in which insulation scenario would be preferable for reducing climate change potential, when comparing insulation optimization between static energy projection and dynamic energy projection, confirms the hypothesis that accounting for dynamic heat energy supply will result in the indication of a lower optimum level of insulation. A further understanding of this energy optimization shift can be seen in the curve shown in Figure 5. This figure illustrates that the shift in terms of contributions to climate change over time from a building system modeled relying on a static energy mix and an energy mix that is modeled after projected change in the supply will diverge exponentially as the temporal scope of the assessment increases. This comes from compounding the reduced impact of heating over time. For example, the impact of heating in 2050 is projected to contribute to climate change only about $64 \%$ as much as heating in 2015 , according to our assessment using political projections of change in energy production mix described by Rasmussen (2012). And, in 2090 heating is projected to contribute to climate change only about $23 \%$ as much as heating in 2015 , according to our assessment using a linear projection of the climate change impact contributions based on the political projection of change in production method between the years 2015 and 2050 (Rasmussen 2012). While both static and dynamic energy scenarios show a minimum climate change contribution in the middle-range of insulation scenarios, the differences between the minimum climate change potential and the climate change potential of higher levels of insulation becomes more pronounced with the introduction of a dynamic energy mix. As 
presented in Figure 2 the potential impact of inadvertent over-insulation was hypothesized, while in Figure 6 this hypothesis was further confirmed by comparing the marginal impacts between DREM5 and DREM6 based on a 2015 construction year.

Table 1: ILCD 2011 climate change potential impact comparison based on construction year and insulation scenario for static and dynamic energy mix DREM scenarios

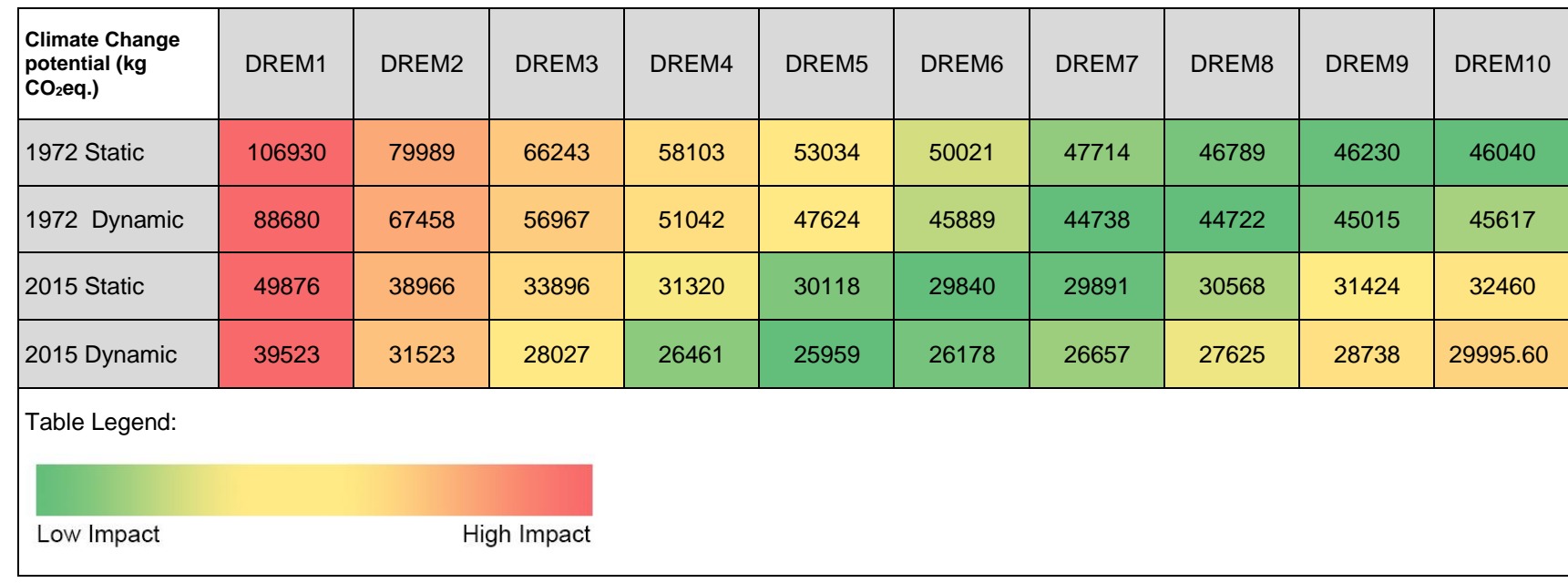

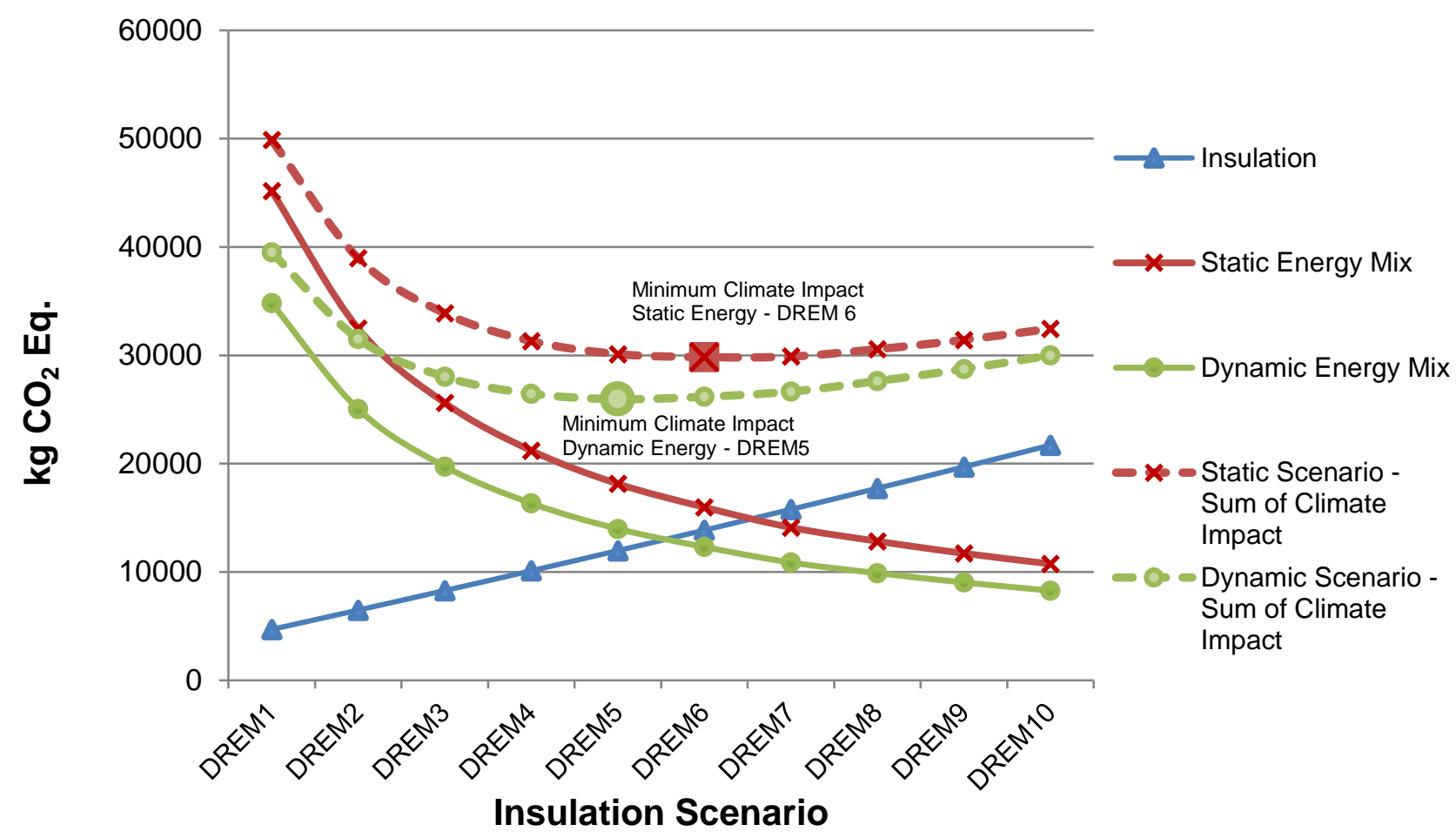

Figure 4: Life cycle impact curve comparison of ILCD 2011 midpoint climate change for static and dynamic energy 2015 construction year scenarios. The enlarged data point marker on summation lines indicate the insulation scenario with the minimum climate change potential. This shows that when dynamic energy mix is applied lower insulation level (DREM5) are preferred for the same building type. 


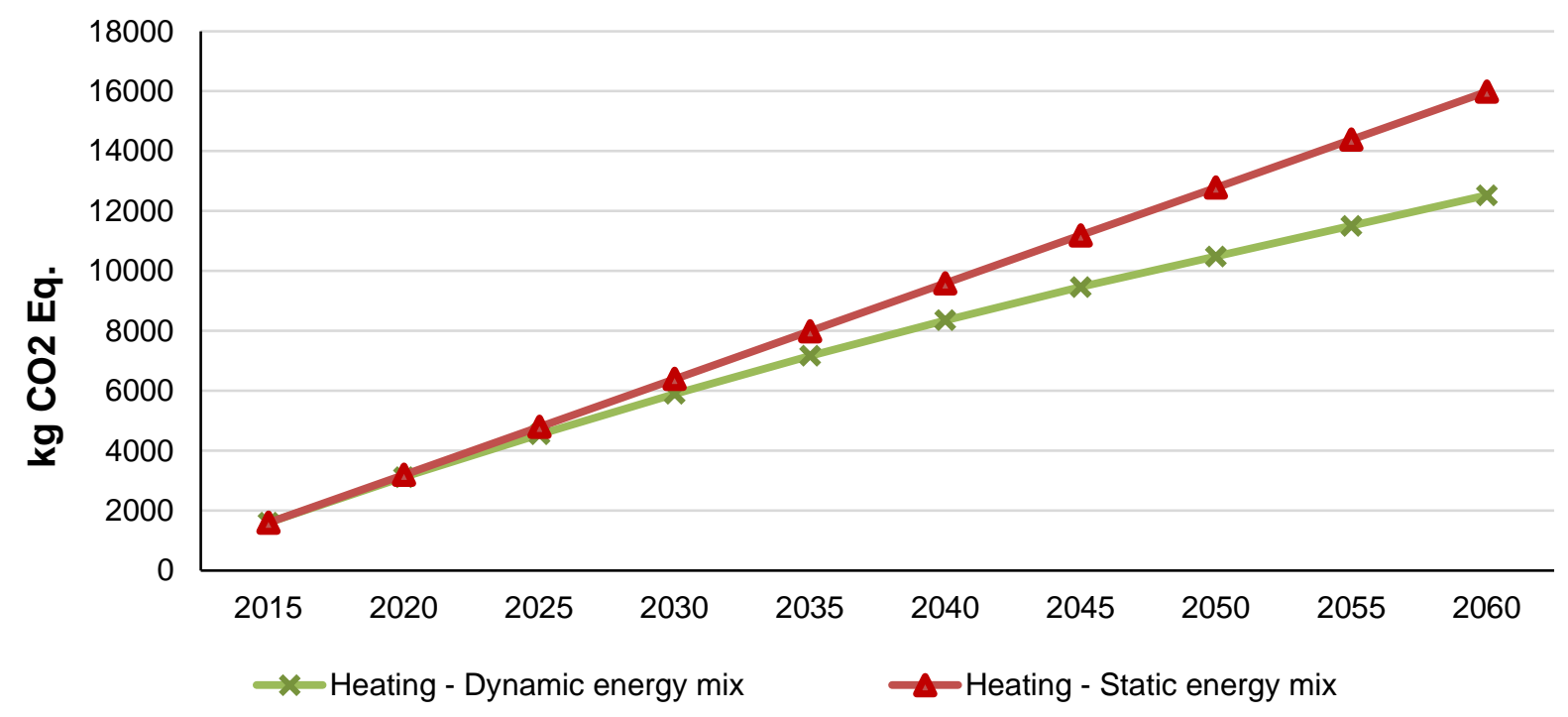

Figure 5: Comparison of accumulated contribution to climate change from heating throughout the service life of a house constructed in 2015 for the DREM6 scenario. A similar relationship exists between the static and dynamic energy production scenarios for all other insulation scenarios, so the analysis of only DREM6 was considered sufficiently representative.

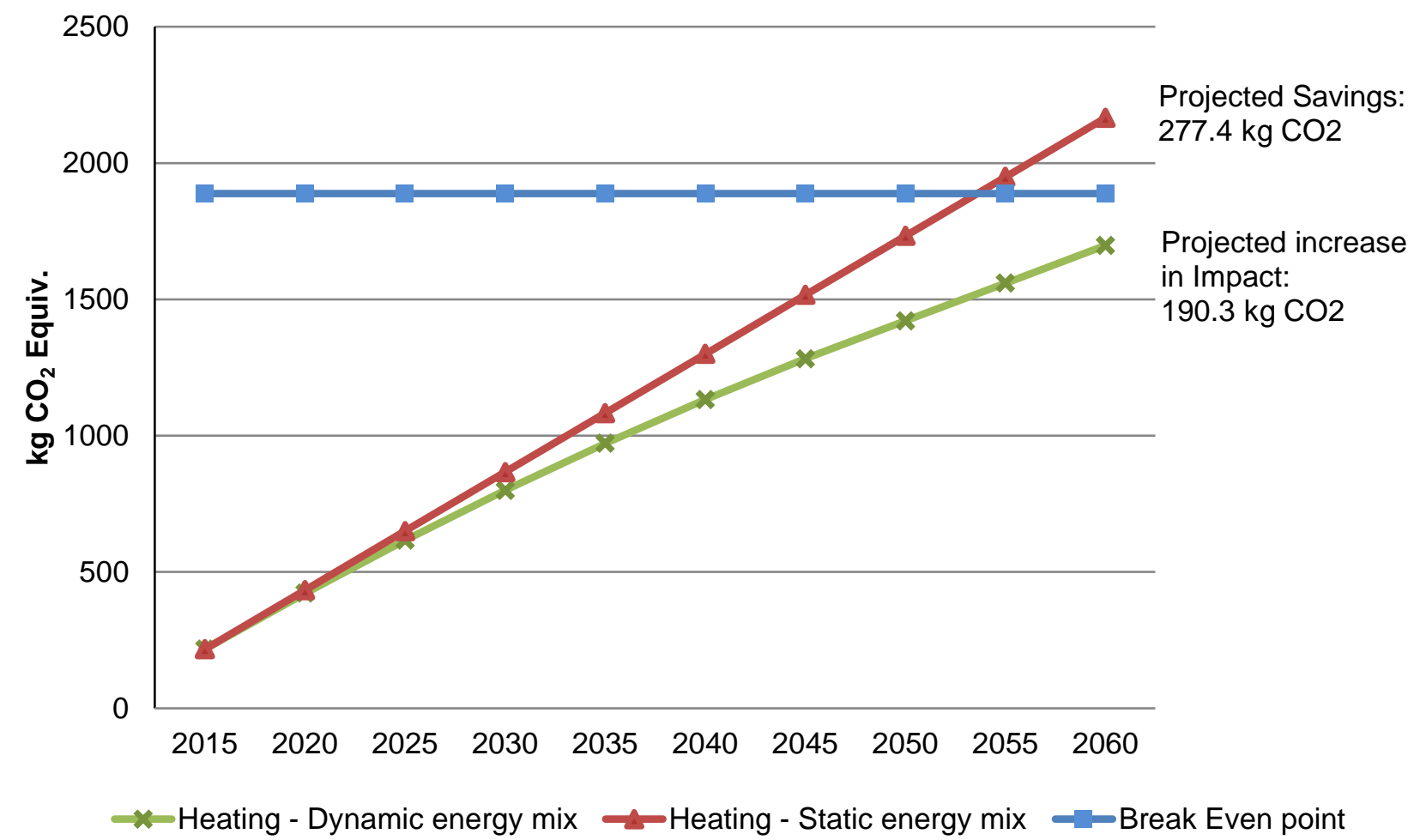

Figure 6: Climate change potential variation between DREM5 and DREM6 comparing static and dynamic energy mix with the variance in climate change potential between DREM5 and DREM6 induced due to the difference in quantity of insulation and associated marginal building materials indicated as the break even point 


\subsection{Discussion}

In assessing the environmental impacts related with heating of a single family home, the balance between environmental impact of insulation and providing heat is not always straightforward. Despite the inherent complexity of the assessment, some elements, such as the physical relationship between incremental increase in insulation compared to that insulation's potential reduction in building heat loss are well understood physical relationships (Figure 1), this interrelation gives good insight into the difficulties associated with making higher levels of building insulation environmentally beneficial as the depth of insulation becomes large. The relationship illuminated for climate change potential by the life cycle impact curve (Figure 4) is indicative of this insulation increase issue. Particularly as the dynamic energy climate change contribution curves toward a smaller impact over time (as described in Figure 5), it becomes more difficult to justify super-insulation of buildings, barring some other shift such as a change in the fuel source thermal energy for the production of mineral wool insulation.

It is also considered possible that some choices made in this study could affect the interpretation of the results of this study. The LCA judging the midpoint results across all impact categories show a significant variation in preferred insulation level when all midpoints are considered for the selection. In order to compare the impact magnitude across different impact categories, normalization of the data must be conducted. In order to do this, further analysis and characterization of the midpoint impact categories should be carried out in order to avoid over-focusing and missing other large impacts (Kägi et al. 2016). However, there is a large amount of uncertainty involved in the normalization of impacts, and to maintain a manageable scope of this study, such an undertaking was left out of our study. 
While the decision to focus on climate change impacts has the potential of missing other significant environmental impacts, it allows for the use of data with a high level of certainty, as climate change data is well documented in the impact assessment methods (Hauschild et al. 2013). Furthermore, the focus on this category aligns with the political agenda that underscores Danish policy regulating energy production and insulation levels (Aggerholm 2013; DEA 2011). The focus decision further allows for the results to enable a direct assessment of the effectiveness of the insulation regulation in terms of achieving politically mandated greenhouse gas emission reduction goals.

The results of our study indicate that current Danish building regulations, up to 2015, promote environmentally beneficial design through (gross) reduced greenhouse gas emissions by relying increased levels of insulation. However, the next step in energy reduction (Building Class 2020), which is intended to come into effect as a regulation requirement in 2020, is likely to promote levels of insulation that are environmentally detrimental seen from a gross greenhouse gas emissions perspective. The comparison shown in Table 1 further reveals a trend indicating that an environmental optimization will lead to reduced levels of insulation for construction done in the future. The understanding of this relationship is vital for both the government, in assuring promotion of a policy that achieves its goals, and for the insulation manufacturing industry, in assessing the environmental performance of its production process in order to ensure continued relevance of insulation products into the future.

\subsection{Validation of the LCA results}

The main source of uncertainty is the actual product system model and its inventories used to quantify the impact potentials resulting from district heat production and mineral wool production. In order to verify the processes in the used product-system model, 
climate change impact potentials calculated using the custom processes were compared with climate change impact potential values from the Danish government, previous life cycle assessment published in the scientific literature, and the insulation industry. The DEA reports the actual greenhouse gas emissions of $1 \mathrm{GJ}$ of delivered district heat as 32 $\mathrm{kg} \mathrm{CO} 2$ equivalent (Energistyrelsen 2015). The custom process for production and delivery of heat used in our model (pls. see Table S5 in SI), indicates a slightly larger environmental impact for district heat production at $33.2 \mathrm{~kg} \mathrm{CO} 2$ equivalent per GJ. This difference could be due to some of the simplifications relating to fuel sources as well as various modelling choices applied in the characterization method. The difference is less than $4 \%$ and is thus considered acceptable.

For mineral wool, the production process used in our model has been directly used from the Ecoinvent database (pls. refer to Table S6 for a detailed overview of the process applied). The environmental impact potentials of the mineral wool production process presented in Table S6 were compared with impact potentials reported by the industry and life cycle assessments reported in the scientific literature. According to the Ecoinvent mineral wool process, the production of $1 \mathrm{~kg}$ of mineral wool results in a climate change impact potential of $1.34 \mathrm{~kg}$ of $\mathrm{CO}_{2}$ Equivalent. Schmidt et al. (2004) in their life cycle assessment of insulation materials calculated the climate change impact potential of the production of $1 \mathrm{~kg}$ of mineral wool as $1.22 \mathrm{~kg}$ of $\mathrm{CO}_{2}$ equivalent, and this is the same number that is used by a key European mineral wool producer in their promotional materials (Rockwool 2016). While these numbers indicate an app. 9.8\% difference in the greenhouse gas emission resulting from production of $1 \mathrm{~kg}$ mineral wool, it is likely that differences in the way packaging is accounted for as well as differences in characterization factors, could account for the disparity. Conversely, Ökobau (2004) reports climate change 
impact potential for the production of $1 \mathrm{~kg}$ of mineral wool as $1.56 \mathrm{~kg}$ of $\mathrm{CO}_{2} \mathrm{eq}$. As was also the case for the energy production, the differences between the climate change impact value used in this study for the production of mineral wool in comparison with other values found in literature and from the industry are considered acceptable, particularly as the value used in this study falls in the middle range of values found in other literature.

\subsection{Sensitivity analysis}

In order to better understand the impacts of the input values applied in our model on the proportion of each source of energy in the district heating system, a sensitivity analysis was performed using the 2015 DREM5 dynamic energy scenario due to its most average values for energy mix. Due to the linear nature of the system, a one factor at a time deterministic sensitivity analysis was used (Saltelli 1999), varying each of the 10 thermal energy production sources that make up the district heating by increasing each individually by $10 \%$. This ratio applying the 2015 DREM5 dynamic energy basis scenario was calculated by the following relationship adapted from formulae given Saltelli's assessment of sensitivity analysis methods (1999),

$$
S R_{n}=\frac{\frac{O P_{j}(\Delta)-O P_{j}}{O P_{j}}}{\frac{\Delta I P_{n}(\Delta)-I P_{n}}{I P_{n}}}
$$

where, $S R_{n}$ is the sensitivity ratio of input parameter $n, O P_{j}$ is the magnitude of output parameter $j, O P_{j}(\Delta)$ is the magnitude of output parameter $j$ after an incremental $(\Delta)$ change to input parameter $n, I P_{j}$ is the magnitude of input parameter $n, \Delta I P_{j}$ is incremental $(\Delta)$ change (10\%) to input parameter $n$. As all energy sources were varied by $10 \%$ individually thus quantifying the denominator of eq. 1 as $\Delta$ Input/Input $=0.1$. Our sensitivity 
analysis was carried out using the 2015 dynamic energy scenario as base scenarios in terms of energy source proportions.

The sensitivity analysis shows that there are energy production processes that are able to more affect the environmental impact potentials of heat production more than others. The obtained SRs for each of the energy sources ranged from $13.38 \%$ (for coal) to $-14.68 \%$ (for waste). The range of the SRs (see Table 2) reveals that certain energy sources should be prioritized higher than others in relation to inventory compilation.

Table 2: Sensitivity factor by energy source

\begin{tabular}{|c|c|c|c|c|c|c|c|c|c|c|}
\hline $\begin{array}{c}\text { Impact } \\
\text { category }\end{array}$ & Biogas & Biomass & Coal & $\begin{array}{c}\text { Electric } \\
\text { boiler }\end{array}$ & $\begin{array}{c}\text { Geotherm } \\
\text { al }\end{array}$ & $\begin{array}{c}\text { Heat } \\
\text { Pump }\end{array}$ & Natural gas & Oil & Solar & Waste \\
\hline $\begin{array}{c}\text { Climate } \\
\text { change }\end{array}$ & $-0.38 \%$ & $-9.00 \%$ & $13.38 \%$ & $1.89 \%$ & $2.11 \%$ & $7.27 \%$ & $-0.76 \%$ & $3.96 \%$ & $-3.51 \%$ & $-14.68 \%$ \\
\hline
\end{tabular}

\subsection{Limitations of the study}

This study is based on secondary data collected from wide variety of literature such as scientific articles, industrial reports and regulatory documents. Attempts have been made to make this study as transparent as possible and to estimate the environmental impact values of the insulation and energy production as precisely as possible. However, to arrive at these estimates some modelling choices and assumptions have been made. These have induced some level of uncertainty propagating all the way to the results and the results of the present study must thus be interpreted in the light of these assumptions and limitations. 
The data used in our study for the formulation of energy mix includes a range of uncertainty. For the 1972 construction year scenarios, actual recorded data was used. Because of this, there is low uncertainty regarding the composition of the energy mix in these scenarios. For the 2015 construction year scenarios, however, forecast data is used for the energy mix composition. This involves much higher levels of uncertainty. But, because of the long service life of buildings, there is no way of avoiding the use of some form of forecast for energy supply when conducting an LCA. This was one of the primary factors that led to the formulation of our study. The dynamic energy scenario using political forecasts, is thus intended to reduce uncertainty as much as feasible and in this way increase the validity of the LCA of building insulation.

In addition, the following list covers some of the major assumptions and limitations:

i. One of the significant elements affecting the outcome of this study is the selection of processes contributing to the Danish energy supply and thus to district heating and power production as well as the process chosen to represent the mineral wool insulation used in Denmark. An area where the selected process used for modelling would ideally have a better fit in relation to the represented sector is in the biomass portion of the energy supply. Danish biomass energy production has on average (since 1972) been made up of $38.9 \%$ straw, $30.7 \%$ wood chips, $21.3 \%$ wood pellets, and $9.1 \%$ waste wood, and the majority of this energy is produced in combined heat and power production facilities (Danish Energy Agency 2015). There are, however, no processes in the Ecoinvent 3.2 database for straw, wood pellets, or waste wood combusted in a CHP plant. Therefore, wood chips in a CHP plant was chosen to represent the biomass category as a whole. While not perfectly representative, using the wood chips in a CHP plant as a representative process is assumed to be superior 
to relying on aggregating processes using individual fuels that more closely reflect actual fuel-type consumption, but in a conventional heat production facility instead of a CHP plant. This assumption was made due to the potential for loss of validity from failing to appropriately allocate impacts by using conventional heat production likely being much higher than the potential for loss of validity caused by using wood chips to represent all biomass in a CHP heat production facility. Should a process, or processes able to be aggregated, more representative of Danish biomass based heat production compatible with other Ecoinvent energy processes become available, this would allow for more precise results. Without more representative data being available, the use of wood as a proxy for other biomass sources was preferred over mixing data production methodologies, as the uncertainties introduced by use of multiple process creation methodologies could be even larger and yield more unreliable results than the results obtained relying on wood as a proxy biomass.

ii. Similarly, there is slight misalignment among the building material processes. The process for production of mineral wool was developed representing production of a mineral wool with a density of $100 \mathrm{~kg} / \mathrm{m}^{3}$ instead of the $41 \mathrm{~kg} / \mathrm{m}^{3}$ density that is used as an average density for the purposes of this study. The process is intended to represent medium to low density mineral wool, and is thus used appropriately, but this results in an under-representation of the impact of packaging material from this process (i.e. more the more dense material can be packed more densely), but the overall difference is considered insignificant and hence outside the scope of this study to account for.

iii. The heat supply for the reference house was chosen as district heating. This means that this study is only representative for houses connected to the district heating grid, although this represents a majority, 62.4\%, of Danish households (Dansk Fjernvarme 
2015). The choice to use district heating as the energy source was based upon fact that the environmental impact potentials of the self-supply heat production methods are well documented in the Ecoinvent database (Weidema et al. 2013). Because of this, there is little to be gained from making a such static impact balances, and due to discounting allowances in the Danish building code, houses connected to the district heating system are legally allowed a different (increased) energy usage for heating while maintaining the same energy classification as houses using other sources of energy for heat. This different usage would result in different insulation scenarios being necessary to meet the same regulatory level when comparing self-supply and district heating connected houses. Because of the existing documentation along with the potential for conflation through the inclusion of self-supply, the environmental impact balances for self-supply heat production methods are not assessed in this study.

iv. Some assumptions relating to the district heating grid were also needed in order to complete the assessment. A $20 \%$ transmission loss was assumed, which may affect the outcome of the study (Danish Energy Agency 2014). While this number might be indicative of the district heating system as a whole, at a local level heat loss ranges from approximately $8 \%$ to $40 \%$ have been reported in Denmark (State of Green 2015). This large range means that an individual house may actually have net impacts resulting from the insulation-heating tradeoff that differ significantly from this study. As the distribution network is updated in the coming years, more efficient networks are likely to be installed bringing average losses for the system down over time. Ideally this efficiency shift could also be captured in a dynamic distribution process, but because of lack of reliable information on the potential for the implementation of more efficient delivery grids, such a dynamic process was not implemented in this study. The result of 
this is that the impacts of heating might appear slightly larger than they will be in reality throughout the service life of a building built today.

v. While it is beyond the scope of this study to test for such issues, there is a chance that the selection of OpenLCA software for conducting this LCA might have had an effect on the results, as it has been noted in studies comparing the impact potentials obtained from more or less random selected processes that the selection of LCA software can affect the outcome of a study (Speck et al. 2015). However, given that the impacts recorded in this LCA align well with existing literature, it is considered unlikely that such an issue has had any considerable impact on this study.

vi. It is also possible that the energy use estimates made using the BE10 software could have an effect on the results of this study. The BE10 building energy model developed by the Danish Building Institute, which includes both static and non-static energy parameters based on a single thermal zone (Aggerholm and Sørensen 2011). The generalization of the single thermal zone as well as decisions, such as including a standard water heater leaking heat into the home, could have an effect on the resultant energy requirements. However, such choices were made based on the available best practices for use with BE10 (Aggerholm and Sørensen 2011). Also, given the ability to use BE10 for Danish building regulation compliance regarding energy consumption, it was concluded that the energy demand estimates from BE10 were of most relevance to this study (DEV, 2010). It is also assumed that any other energy loss model would have similar potential for uncertainty, so while it is possible that the losses calculated in BE10 might vary from real energy losses, it is concluded that BE10 is the best possible choice and the potential for variance in calculated energy loss is considered acceptable for the purpose of this study. 
vii. The selection of mineral wool insulation for all applications in the building (slab, wall, and roof) was made due to the advantageous, in regard to environmental impact, reputation of mineral wool insulation. This resulted in the application of mineral wool insulation in the slab, where other insulation types, such as expanded polystyrene might typically be applied. The result of this is a slight undervaluation of the impacts of insulation with regard to standard building practice, but this known variance was considered preferable to introducing another type of insulation because of the inherent potential of conflation in impacts between the mineral wool and whatever other insulation material might have been applied to the slab.

viii. Finally, the service life of a building has a direct relationship in regards to the net environmental impact of insulation. While 50 years was chosen based on standard practice, an assessment of building service life by location, typology, etc. could significantly improve the applicability to local building practices in results of this study. Such data is currently unavailable, and it is outside the scope of the present study to develop such a data set, but the assumption of a 50-year life-span is considered sufficiently representative. Also, the service life of a building could significantly affect the preference in insulation scenario. Hence, in case the service life of a building actually was longer, it could be possible to increase levels of insulation while maintaining environmental benefit. On the other hand, in case the discrepancy between fixed and dynamic energy scenarios becomes more pronounced over service life of a building, the aggregated impact of the unbalanced use of insulation would become more pronounced. However, if the progression toward reduction in the contribution to climate change attributed to heating continues at its current rate, the insulation levels suggested as optimal by our study should continue to be the optimal level even if the 
service life were extended to 75 years (please see Figure S5 in SI). It is further possible that a building's use phase might be much less than 50 years, if for example it is destroyed in a natural disaster. Because of these considerations and their balance, the use of the industry standard 50-year service life was concluded to be the best current option, but should evidence of a more accurate service life become available, such information could play a critical role in the determination optimal levels of insulation.

\subsection{Alternative solutions}

While our results indicate that super-insulated houses are unlikely to be environmental beneficial given current mineral wool production methods, it is possible that significant steps of the production of mineral wool may change in the future. One of the primary elements that could change the environmental performance of mineral wool production is the fuel used to generate thermal energy for the production. Assessing the current production process of mineral wool, approximately $60 \%$ of the primary energy used comes from coke, which is primarily burnt in a cupola furnace during the mineral melting process (Deutsche Rockwool 2012). This could be replaced with other sources of heat such as biomass, which most likely will reduce the greenhouse gas emissions related with mineral wool production. If such changes were to be implemented, it is likely that much higher levels of insulation would be environmentally beneficial given the reduced economic impact of insulation production.

\subsection{Further study}

There are several areas of further study that ought to be undertaken in the near future to address some of the questions that remain unanswered in this work. The most obvious is a multivariate analysis of all ILCD 2011 midpoint impact factors, instead of climate change 
impact alone. Such an analysis could allow for particular political or environmental concerns to be taken into account to allow for a better fit of scenario preferences to local concerns. An assessment of the full set of indicators would further allow for a more holistic understanding of the impacts of each insulation scenario, as it is possible that focus on a single impact category could fail to recognize a significant issue that is only seen in another impact category (Kägi 2016). Given the direct relationship between building service life and the amortization of the impact of construction materials, further study of expected building service lives would significantly improve estimates of service life scenarios that better reflect the real-world building stock. Also, the use of BE10 allows for easy incorporation of alternative climate data, and this could potentially allow for the generation of climate change scenarios using the METEONORM IPCC climate change projection data sets. Using alternative prospective meteorological data, it is considered possible that the shift in temperature over time due to climate change could further affect insulation scenario preference (Remund 2011). The inclusion of other building typologies such as row houses, multi-family dwelling units, and commercial buildings as well as other including new types of insulation materials, building locations, and climates could help to make the results more locally applicable as well. In addition, an expansion to include other sources of heat, such as self supply with heat pumps, geothermal, solar, oil, electric resistance heaters, etc. would allow for a broader applicability of the results. Furthermore, a more in depth political plan and increased access to process data could allow for a more representative district heating production mix. However, it is considered likely that such research could only be undertaken with the cooperation of political and private entities.

Last but not least, it is important to consider that this assessment has been conducted on product level and the energy performance assessment hence only focuses on the terminal 
of the energy grid - the building. Because of this, it is important to remember that further insulation is an easy way to make more thermal energy available for other purposes and thus a greening of the thermal energy grid can be conducted by lowering the demand for for energy through lowering the demands through super-insulation of buildings and hereafter removing the surplus production by removing the most greenhouse gas burdensome technologies. However, thermal insulation is only one of many factors, among others such as self supply and passive heating strategies, that might lead to reduced demand for thermal energy. Because of these complicating factors, the consequences of how such a strategy, that deviates from the current trajectory of insulation regulations, will perform seen from a greenhouse gas perspective on an energy grid level remains unresolved and unaddressed.

\subsection{Conclusions}

In comparing the climate change potential of heating and insulating a single family home seen from an attributional perspective on product (i.e. single family house) level, it is clear that the changes made in the production of Danish energy have had a significant impact on the climate change potential of heat provision through district heating over the last several decades. Through the systematic investigation carried out in the present study, the hypothesis that creating super-insulated houses will reduce the environmental impact of our homes has proven to be incorrect in case the home is connected to district heating. Also, very high levels of insulation, such as those that can be used to meet regulations like the Danish Building Class 2020, are not likely to be environmentally detrimental if constructed today, but also would most likely have detrimental if built in the 1970s. When put in the context of current construction, this study indicates that there is a net global 
warming impact of over insulating a home which can be extrapolated to a potential for the whole Danish new single family home market, which is presently comprised of 3690 annual single family home starts (Statistics Denmark 2016). Based on the annual Danish new single family home market for 2015 , the construction of only insulation-optimized homes (DREM5) versus the construction of only super insulated homes (DREM8) would result in an additional impact of appx. 6,147 tons of $\mathrm{CO}_{2}$ eq. annually. A better understanding of this full relationship could be determined through a multiple criteria decision analysis, but the general trend towards lower levels of insulation being more beneficial for climate change potential in the future allows some conclusions and considerations to be made even without such an analysis. Such analysis could also be carried out for other geographical areas (countries or regions) allowing for the utility of using a dynamic energy supply to be applied to other regions, potentially with greater significance in countries that are just beginning to realize changes in their energy supply. Our study also finds that, in order to promote a further reduction of greenhouse gas emission related impacts and hence climate change impacts from heating of the Danish building stock, a reduction of the greenhouse gas burden from the production of insulation could be of obvious interest. A shift away from the dominating use of coke to a greener source of energy for thermal energy in the production of mineral wool could change the results of this study entirely, allowing for greater levels of insulation while maintaining climate change impact benefit. Furthermore, in order to create a building policy that better achieves the goal of environmental protection, both the production and use phase of building materials should be evaluated taking into account changes over time to the processes when such changes are known or can be forecasted with a reasonable level of certainty. Findings based on such life cycle based dynamic assessments (such as the one 
that is presented in our study) will help policy makers, builders, and others with relation to the home construction industry avoid unintentional promotion of environmentally detrimental building practices through policies.

\section{Acknowledgements:}

The second author acknowledges Postdoctoral fellowship received from Technical University of Denmark (DTU) under the HC Ørsted Postdoc Programme co-funded by Marie Curie Actions (Grant agreement No. 609405).

\section{References}

Aggerholm, S. (2013). Cost-optimal levels of minimum energy performance requirements in the Danish Building Regulations (pp. 22-39). Copenhagen: Statens Byggeforskningsinstitut. Retrieved from http://www.sbi.dk/

Aggerholm, S., \& Sørensen, K. G. (2011). Bygningers energibehov: Beregningsvejledning. Hørsholm: Statens Byggeforskningsinstitut.

Aggerholm, S., \& Sørensen, K. G. (2016). ÆEndringer til tidligere versioner af Be10. Retrieved from http://www.sbi.dk/

Armor, J. N. (2007). Addressing the CO2 dilemma. Catalysis Letters, 114(3), 115-121. doi:10.1007/s10562007-9063-3

Azari, R., Garshasbi, S., Amini, P., Rashed-Ali, H., \& Mohammadi, Y. (2016). Multi-objective optimization of building envelope design for life cycle environmental performance. Energy and Buildings, 126, 524-534. http://doi.org/10.1016/j.enbuild.2016.05.054

Cuéllar-Franca, R. M., \& Azapagic, A. (2012). Environmental impacts of the UK residential sector: Life cycle assessment of houses. Building and Environment, 54, 86-99. doi:10.1016/j.buildenv.2012.02.005

Danish Energy Agency. (2011). Our Future Energy. Copenhagen: Danish Energy Agency. Retrieved from http://www.ens.dk

Danish Energy Agency. (2014). Forudsætninger for samfundsøkonomiske analyser på energiområdet, december 2014. København. Retrieved from http://www.ens.dk/

Danish Energy Agency. (2015). Energy Statistics 2013. Copenhagen: Danish Energy Agency. Retrieved from http://www.ens.dk

Dansk Erhvervs og Vækstministeriet. Danish Enterprise and Construction Authority. (2010). Building Regulations (pp. 126-142). Copenhagen.

Dansk Fjernvarme. (2015). Dansk Fjernvarmes Årsberetning 2014. Kolding: Dansk Fjernvarme. Retrieved from http://www.danskfjernvarme.dk/ 
Deutsche Rockwool Mineralwoll GmbH \& Co. OHG. (2012). Environmental Product Declaration: Stone wool insulating materials in the low bulk density range. Institut Bauen und Umwelt.

Energy Information Administration (2012). Space Heating and Cooling. Retrieved from www.energysavers.gov

Energistyrelsen. (2015). Energistatistik 2014. Copenhagen: Energistyrelsen. Retrieved from http://www.ens.dk

European Commission - Joint Research Centre - Institute for Environment and Sustainability. (2010). International Reference Life Cycle Data System (ILCD) Handbook -- General guide for Life Cycle Assessment -- Detailed guidance. Constraints. http://doi.org/10.2788/38479

Gentil, E., Christensen, T. H., \& Aoustin, E. (2009). Greenhouse gas accounting and waste management. Waste Management \& Research: The Journal of the International Solid Wastes and Public Cleansing Association, ISWA, 27(8), 696-706. http://doi.org/10.1177/0734242X09346702

Green Delta (2015). OpenLCA version 1.4.1. Retrieved from http://openLCA.org

Gustavsson, L., \& Joelsson, A. (2010). Life cycle primary energy analysis of residential buildings. Energy \& Buildings, 42(2), 210-220. doi:10.1016/j.enbuild.2009.08.017

Hauschild, M. Z., Goedkoop, M., Guinée, J., Heijungs, R., Huijbregts, M., Jolliet, O., ... Pant, R. (2013). Identifying best existing practice for characterization modeling in life cycle impact assessment. International Journal of Life Cycle Assessment, 18(3), 683-697. http://doi.org/10.1007/s11367-012-0489-5

Kaynakli, O. (2012). A review of the economical and optimum thermal insulation thickness for building applications. Renewable and Sustainable Energy Reviews, 16(1), 415-425. doi:10.1016/j.rser.2011.08.006

Kägi, T., Dinkel, F., Frischknecht, R., Humbert, S., Lindberg, J., De Mester, S., ... Schenker, U. W. (2016). Session "Midpoint, endpoint or single score for decision-making?"-SETAC Europe 25th Annual Meeting, May 5th, 2015. International Journal of Life Cycle Assessment, 21(1), 129-132. http://doi.org/10.1007/s11367-015-0998-0

Ibn-Mohammed, T., Greenough, R., Taylor, S., Ozawa-Meida, L., \& Acquaye, A. (2013). Operational vs. embodied emissions in buildings - a review of current trends. Energy and Buildings, 66, 232-245. doi:10.1016/j.enbuild.2013.07.026

Ökobau (2004). Process Data set: Mineral wool (Facades); 46 kg/m3 (en). Retrieved from http://www.oekobaudat.de/

Papadopoulos, A. M., \& Giama, E. (2007). Environmental performance evaluation of thermal insulation materials and its impact on the building. Building and Environment, 42(5), 2178-2187. http://doi.org/10.1016/j.buildenv.2006.04.012

Rasmussen, F. N. (2012). Certification of sustainable buildings in a life cycle assessment perspective. Lyngby: Danmarks Tekniske Universitet.

Remund, J., Müller, S. C., Schilter, C., \& Rihm, B. (2011). The use of Meteonorm weather generator for climate change studies. EMS Annual Meeting Abstracts, 7, 46625.

Richman, R., Pasqualini, P., \& Kirsh, A. (2009). Life-cycle analysis of roofing insulation levels for cold storage buildings. Journal of Architectural Engineering, 15(2), 55-61. doi:10.1061/(ASCE)10760431(2009)15:2(55)

Rockwool A/S, (2016). Carbon Footprint Og Positiv Co2 Balance. Retrieved February 29, 2016, from http://www.rockwool.dk/ 
Sartori, I., \& Hestnes, A. G. (2007). Energy use in the life cycle of conventional and low-energy buildings: A review article. Energy \& Buildings, 39(3), 249-257. doi:10.1016/j.enbuild.2006.07.001

Saltelli, A. (1999). Sensitivity analysis: Could better methods be used? Journal of Geophysical Research, 104(D3), 3789. http://doi.org/10.1029/1998JD100042

Schiavoni, S., D'Alessandro, F., Bianchi, F., \& Asdrubali, F. (2016). Insulation materials for the building sector: A review and comparative analysis. Renewable and Sustainable Energy Reviews, 62, 988-1011. http://doi.org/10.1016/j.rser.2016.05.045

Schmidt, A. C., Jensen, A. A., Clausen, A. U., Kamstrup, O., \& Postlethwaite, D. (2004). A comparative life cycle assessment of building insulation products made of stone wool, paper wool and flax: Part 1:

Background, goal and scope, life cycle inventory, impact assessment and interpretation. The International Journal of Life Cycle Assessment, 9(1), 53-66. doi:10.1007/BF02978536

Schmidt, A. C., Jensen, A. A., Clausen, A. U., Kamstrup, O., \& Postlethwaite, D. (2004). A comparative life cycle assessment of building insulation products made of stone wool, paper wool and flax: Part 2:

Comparative assessment. The International Journal of Life Cycle Assessment, 9(2), 122-129. doi:10.1007/BF02978571

Speck, R., Selke, S., Auras, R., \& Fitzsimmons, J. (2015). Choice of life cycle assessment software can impact packaging system decisions. Packaging Technology and Science, 28(7), 579-588.

doi:10.1002/pts.2123

State of Green (2015). District heating-Danish experiences. Retrieved February 29, 2016, from http://www.ens.dk/

Statistics Denmark (2016). Residential Construction (not adjusted for delays) by use, phase of construction, region, builders and time. Retrieved from http://www.statbank.dk/

Väntsi, O., \& Kärki, T. (2014). Mineral wool waste in Europe: A review of mineral wool waste quantity, quality, and current recycling methods. Journal of Material Cycles and Waste Management, 16(1), 62-72. http://doi.org/10.1007/s10163-013-0170-5

Weidema, B. P., Bauer, C., Hischier, R., Mutel, C., Nemecek, T., Reinhard, J., ... Wernet, G. (2013). Overview and methodology: Data quality guideline for the ecoinvent database version 3. Ecoinvent Report 1(v3). St. Gallen: The ecoinvent Centre 